\title{
Two Year Outcomes of "Treat And Extend" Intravitreal Therapy Using Aflibercept Preferentially for Neovascular Age-Related Macular Degeneration
}

Barthelmes, Daniel ; Nguyen, Vuong ; Daien, Vincent ; Campain, Anna ; Walton, Richard ; Guymer, Robyn ; Morlet, Nigel ; Hunyor, Alex P ; Essex, Rohan W ; Arnold, Jennifer J ; Gillies, Mark C ; Fight Retinal Blindness Study Group

DOI: https://doi.org/10.1097/IAE.0000000000001496

Posted at the Zurich Open Repository and Archive, University of Zurich ZORA URL: https://doi.org/10.5167/uzh-140584

Journal Article

Originally published at:

Barthelmes, Daniel; Nguyen, Vuong; Daien, Vincent; Campain, Anna; Walton, Richard; Guymer, Robyn; Morlet, Nigel; Hunyor, Alex P; Essex, Rohan W; Arnold, Jennifer J; Gillies, Mark C; Fight Retinal Blindness Study Group (2018). Two Year Outcomes of "Treat And Extend" Intravitreal Therapy Using Aflibercept Preferentially for Neovascular Age-Related Macular Degeneration. Retina, 38(1):20-28.

DOI: https://doi.org/10.1097/IAE.0000000000001496 


\section{TWO YEAR OUTCOMES OF “TREAT AND EXTEND” INTRAVITREAL THERAPY USING AFLIBERCEPT PREFERENTIALLY FOR NEOVASCULAR AGE-RELATED MACULAR DEGENERATION}

DANIEL BARTHELMES, MD, PhD, $* \dagger$ VUONG NGUYEN, PhD,$\dagger$ VINCENT DAIEN, MD, PhD, $\dagger+$ ANNA CAMPAIN, PHD, $\dagger$ RICHARD WALTON, MSC, $\dagger$ ROBYN GUYMER, MBBS, PHD,$\S$ NIGEL MORLET, MBBS, I ALEX P. HUNYOR, MBBS, $\dagger^{* *}$ ROHAN W. ESSEX, MBBS, $\dagger \dagger$ JENNIFER J. ARNOLD, MBBS (Hons), + \$ MARK C. GILLIES, MBBS, PhD $\dagger$ THE FIght Retinal Blindness STUDY GROUP

Purpose: To report 24-month outcomes of a treat and extend (T\&E) regimen using aflibercept in eyes with neovascular age-related macular degeneration.

Methods: This was a database observational study that included treatment-naive eyes with neovascular age-related macular degeneration tracked by the Fight Retinal Blindness! outcome registry completing 24 months of sole monotherapy with aflibercept treatment under a T\&E regimen between November 1, 2012 and January 31, 2014. Locally weighted scatterplot smoothing curves were used to display visual acuity outcomes. Main outcome measures were change in visual acuity at 24 months and number of injections and visits during the study period.

Results: The study population, identified by reviewing the database, consisted of 136 eyes from 123 patients completing 24 months of follow-up on aflibercept. Mean (SD) age was 77.2 (7.0) years, 59\% were female. Mean visual acuity increased from $61.4(\sim 20 / 60$; SD 17.4) letters at baseline to 67.4 ( 20/45; SD 17.7) letters at 24 months (+6.0 letters [ $95 \%$ confidence interval: 3.3-8.5]; $P<0.001$ ). From baseline to 24 months, the proportion of eyes with visual acuity $\geq 70$ letters $(20 / 40)$ increased $(40 \%-58 \%, P<0.001)$ and the proportion of eyes with visual acuity $\leq 35$ letters $(20 / 200)$ remained the same $(10 \% ; P=0.547)$. Ninety-eight per cent of eyes starting with visual acuity $\geq 70$ letters $(20 / 40)$ were able to maintain this up to 24 months. From the first to the second year of treatment, the mean number of injections (7.8 [2.1] vs. $5.7[2.6] ; P<0.001)$ and visits (8.7 [1.7] vs. $6.5[2.4] ; P<$ 0.001 ) decreased for eyes completing 24 months of treatment. When data from 60 eligible eyes that did not complete 2 years follow-up, along with 14 eyes that switched to ranibizumab, were included using last observation carried forward, the mean change in visual acuity from baseline was +5.6 letters (95\% confidence interval: $3.3-7.7$ ).

Conclusion: These data indicate that eyes treated with aflibercept, as a sole therapy, in routine clinical practice with a T\&E regimen can achieve good visual outcomes while decreasing the burden of treatments and clinic visits.

RETINA 0:1-9, 2017

\begin{abstract}
Anti-vascular endothelial growth factor (VEGF) vascular age-related macular degeneration (nAMD). Pivotal clinical trials demonstrated efficacy in visual outcomes for aflibercept, ${ }^{1}$ bevacizumab, ${ }^{2}$ and ranibizumab, ${ }^{3,4}$ mostly using fixed treatment regimens. ${ }^{5,6}$
\end{abstract}

Since fixed, especially monthly, treatment schedules carry a high burden of treatment, variable treatment regimens, which are usually based on the activity of neovascular disease being treated, have evolved. Two different regimens are commonly used: pro re nata $(\mathrm{PRN})$ and treat and extend (T\&E). In the PRN 
approach, anti-vascular endothelial growth factor treatment is given only when signs of activity of the choroidal neovascular $(\mathrm{CNV})$ lesion are observed, whereas T\&E entails treatment irrespective of CNV activity but at progressively increasing intervals when no evidence of ongoing disease activity is seen, with the aim of increasing the interval between treatments without allowing reactivation of the CNV. The Comparison of AMD Treatments Trials, The Study of Ranibizumab Administered Monthly or on an As-needed Basis in Patients With Subfoveal nAMD (HARBOUR) trials and The Neovascular Age-related Macular Degeneration Database Report 1 showed that good visual results could be achieved using PRN dosing, yet monthly monitoring was still required-thus reducing the number of injections but not necessarily the number of clinic visits. $^{2,7-10}$ The outcomes of "real world" T\&E treatment for nAMD using ranibizumab have been reported to be comparable with those of fixed dosing, randomized trials, ${ }^{1-16}$ but only few data are available on T\&E approaches in nAMD using aflibercept. We have previously reported the 2-year results of over 1,000 eyes under a T\&E regimen, but this did not include any eyes receiving sole monotherapy with aflibercept. ${ }^{11}$ Here we report the 24-month real-world evidence of a large cohort of patients with nAMD from centers located in Australia, New Zealand, and Switzerland treated by clinicians using aflibercept as a sole therapy in an exclusive $\mathrm{T} \& \mathrm{E}$ regimen.

From the *Department of Ophthalmology, University Hospital Zurich, University of Zurich, Zurich, Switzerland; †The Save Sight Institute, Sydney Medical School, The University of Sydney, Sydney, New South Wales, Australia; $\ddagger$ Montpellier University Hospital, Montpellier, France; §Department of Surgery (Ophthalmology), Centre for Eye Research Australia, Royal Victorian Eye and Ear Hospital, University of Melbourne, Victoria, Australia; qDepartment of Population Health, University of Western Australia, Perth, Western Australia; **Retina Associates, Chatswood, New South Wales, Australia; † Academic Unit of Ophthalmology, Australian National University, Acton, Australian Capital Territory, Australia; and \$ Marsden Eye Specialists, Parramatta, New South Wales, Australia. Supported by a grant from the Royal Australian NZ College of Ophthalmologists Eye Foundation (2007-2009) and a grant from the National Health and Medical Research Council, Australia (NHMRC 2010-2012).

M. C. Gillies is a Sydney Medical Foundation Fellow and is supported by an NHMRC practitioner fellowship, and R. Guymer is supported by a NHMRC Principal research fellowship. D. Barthelmes was supported by the Walter and Gertrud Siegenthaler Foundation Zurich, Switzerland and the Swiss National Foundation. Funding was also provided by Novartis and Bayer. These supporting organizations had no role in the design or conduct of the research. M. C. Gillies and R. Guymer are members of advisory boards for Novartis and Bayer. D. Barthelmes received research grants from Novartis and Bayer. V. Daien received travel grants from Novartis and Bayer. None of the other authors have no any conflicting interests to disclose.

Reprint requests: Daniel Barthelmes, MD, PhD, Department of Ophthalmology, University Hospital Zurich, Frauenklinikstrasse 24, Zurich 8091, Switzerland; e-mail: daniel.barthelmes@usz.ch

\section{Methods}

\section{Study, Design and Setting}

This was an observational study of treatment naive eyes that had received intravitreal therapy for nAMD in routine clinical practice and had been tracked in the Fight Retinal Blindness! (FRB!) outcomes database. ${ }^{17}$ Briefly, the FRB! system was prospectively designed to collect data from each clinical visit, including the number of letters read on a logarithm of the minimum angle (logMAR) of resolution visual acuity chart (best uncorrected, corrected, or pin hole); activity of the $\mathrm{CNV}$, for which a definition is given on the data entry screen (activity is defined as new intra- or subretinal fluid as seen on optical coherence tomography or new hemorrhage); treatment given, if any; ocular adverse events; and whether the eye had received prior treatment for nAMD. Participants to the FRB! Project agreed to report $\geq 80 \%$ of their patients to avoid reporting bias. Treatment decisions and visit schedules were determined by the treating physician in consultation with the patient, which reflects real-world practice. Institutional ethics approval was obtained from the Human Research Ethics Committees of the University of Sydney, the Royal Victorian Eye and Ear Hospital, the Royal Australian and New Zealand College of Ophthalmologists and the canton of Zurich. Ethics committees in Australia and New Zealand approved the use of "opt out" patient consent. The research described adhered to the tenets of the Declaration of Helsinki. Data were collected from contributing practitioners located in Australia, New Zealand, and Switzerland.

\section{Study Population}

For this study, the inclusion criteria required participants to be treatment naive and have started and continued on aflibercept as a sole treatment for nAMD under a T\&E regimen. Eyes that had fewer than 3 injections within the first 12 months were excluded from analysis. Practitioners using the FRB! database were contacted by email to self-report their treatment approaches every year from 2006 to 2014 . The treatment regimens available for selection were monthly, PRN, T\&E, or a combination of these three. The FRB! database was reviewed for cases that started with aflibercept between November 1, 2012 and January 31, 2014. Of the 274 cases identified, 212 were treated under a physician who indicated that they treat using a T\&E protocol.

The primary analysis was conducted on 24-month completers, but we also report baseline characteristics 
and outcomes for noncompleters, switchers, and all eyes as a secondary analysis.

Completers were defined as eligible eyes that completed 24 months of follow-up. Noncompleters were defined as eyes not completing 24 months of follow-up during the study period as of May 27, 2016 when the analysis was conducted, thus allowing at least 3 to 4 months for a follow-up visit to occur after the end of the 24-month observation period to ensure correct classification of eyes as completers and noncompleters in case of treatment interval extension. As an example, an eye entering the study on January 31 , 2014 with no visit from January 31, 2016 to May 27, 2016 was considered a noncompleter. Switchers were defined as having $\geq 2$ consecutive injections of ranibizumab before completing 24 months of follow-up. In these eyes, only visits and visual acuity measurements until the switch were used. A single injection of ranibizumab was not considered a switch as other reasons than actually switching treatments may have been relevant for example availability of the drug, unintentional use that is aflibercept was to be injected but ranibizumab was prepared and eventually used, potentially wrong data entry in the original patient record.

Results, including visual acuity and treatment outcomes, are presented for completers unless otherwise specified. For completers, visual acuity at 24 months was taken as the most recent visual acuity reading within 24 months. When analyzing "all eyes," including completers, noncompleters, and switchers, the last observation carried forward (LOCF) method was used for noncompleters and switchers. ${ }^{18}$

\section{Study Measurements}

Patient age (years) and sex, visual acuity in $\log$ MAR letters, lesion size (in micrometers) and type were recorded at the time of the first injection. All treatments were recorded, along with visual acuity, CNV lesion activity, and ocular adverse events at each visit.

\section{Outcome Measures}

The primary outcome measure was change in mean visual acuity over 24 months after initiating treatment. Secondary outcomes were the mean number of injections and visits over 24 months; the proportion of eyes maintained on treatment intervals of 4 weeks, 5 to 6 weeks, 7 to 8 weeks, 9 to 10 weeks, 11 to 12 weeks, 13 to 14 weeks and $\geq 15$ weeks; the treatment interval extension after the first 3 injections; time and number of injections to first grading of CNV inactivity, retention rates, and ocular safety.

\section{Statistical Analysis}

Descriptive data are described with mean (SD), median (interquartile range [IQR]), number (\%), and 95\% confidence interval (CI) where appropriate. Students $t$, Wilcoxon rank-sum, ANOVA, Kruskal-Wallis, McNemars, Fishers and chi-square tests were used as appropriate to compare baseline characteristics between completers, noncompleters, and switchers. Locally weighted scatterplot smoothing curves were used to analyze visual acuity throughout the follow-up. ${ }^{19}$ Median time to inactivation and noncompletion/switch were calculated using Kaplan-Meier curve analysis. Treatment intervals were categorized into the following 7 groups: 4 weeks (10-34 days), 5 to 6 weeks (35-48 days), 7 to 8 weeks (49-61 days), 9 to 10 weeks (62-76 days), 11 to 12 weeks (77-90 days), 13 to 14 weeks (91-104 days), and $\geq 15$ weeks ( $>105$ days). All analyses were performed using $\mathrm{R}$ version 3.3 .1 with the survival package for Kaplan-Meier analyses. ${ }^{20}$

\section{Results}

From the 343 eyes that started aflibercept monotherapy between November 1, 2012 and January 31, 2014, 274 cases received a minimum of 3 injections and 212 treatment-naive eyes were treated under a physician that had indicated that they use a T\&E protocol. A total of 136 eyes from 123 patients completing 24 months of follow-up (completers) were identified. We also identified 60 treatment-naive eyes that met the selection criteria but did not complete 24 months of follow-up (noncompleters) and an additional 16 eyes that switched to ranibizumab before completing 24 months of aflibercept monotherapy (switchers). Patients were treated by 12 practitioners who self-reported as using exclusively a treat and extend regimen during the study period. There were 2,410 injections given within 24 months for all eyes. Among subjects classified as "aflibercept completers," $29(1.2 \%)$ injections of ranibizumab were administered to 29 eyes. No eye in this group, received more than one nonconsecutive injection of ranibizumab.

\section{Baseline Characteristics}

The baseline characteristics amongst all eyes, completers, noncompleters, and switchers are summarized in Table 1. Mean baseline age (SD) was younger among completers compared with noncompleters (77.2 [7.0] vs. 80.7 [8.2] years $[P=0.005]$ ), whereas the mean baseline visual acuity (SD) was greater (61.4 [17.4] letters [20/60] vs. 50.1 [22.5] letters [20/100]; $P<0.001)$. Completers had more eyes with good 
Table 1. Demographic Characteristics of all Eyes, 24-Month Monotherapy Completers, Noncompleters, and Switchers

\begin{tabular}{|c|c|c|c|c|c|}
\hline & Completers & NonCompleters & Switchers & All Eyes & $P$ \\
\hline No. eyes & 136 & 60 & 16 & 212 & \\
\hline No. patients & 123 & 58 & 15 & 195 & \\
\hline Female (\%) & 59 & 65 & 75 & 62 & 0.377 \\
\hline $\begin{array}{l}\text { Mean baseline age (SD), } \\
\text { years }\end{array}$ & $77.2(7.0)$ & $80.7(8.2)$ & $80.4(8.5)$ & $78.4(7.6)$ & 0.007 \\
\hline $\begin{array}{l}\text { Mean baseline VA } \\
\text { (Snellen; SD) }\end{array}$ & $61.4(20 / 60 ; 17.4)$ & $50.1(20 / 200 ; 22.5)$ & $63.2(20 / 55 ; 18.9)$ & $58.3(20 / 65 ; 19.7)$ & $<0.001$ \\
\hline$V A \geq 70$ letters $(20 / 40 ; \%)$ & 40 & 25 & 44 & 36 & 0.097 \\
\hline $\mathrm{VA} \leq 35$ letters (20/200; \%) & 10 & 25 & 6 & 14 & 0.020 \\
\hline Lesion size (median, IQR) & $2,532(1,675-3,800)$ & $2,753(1,575-3,550)$ & $1950(1,338-3,330)$ & $2,576(1,513-3,725)$ & 0.512 \\
\hline \multicolumn{6}{|l|}{ Angiographic lesion } \\
\hline Occult & 59 & 67 & 63 & 61 & 0.789 \\
\hline Minimally classic & 12 & 10 & 6 & 11 & \\
\hline Predominantly classic & 21 & 15 & 13 & 18 & \\
\hline Other & 7 & 7 & 13 & 8 & \\
\hline Not recorded & 2 & 2 & 6 & 2 & \\
\hline
\end{tabular}

$P$-Values presented are testing for differences between completers, noncompleters, and switchers.

Completers include all eyes completing 24 months of aflibercept monotherapy.

Noncompleters include eyes that have not yet completed 24 months of follow-up and the last VA recorded.

Switchers include eyes that received $\geq 2$ injections of ranibizumab before completing 24 months of aflibercept monotherapy.

All eyes include completers, noncompleters, and switchers.

VA, visual acuity.

The significance level is 0.05 . The bold values indicate a statistically significant difference.

vision (visual acuity $\geq 70 \log$ MAR letters [20/40], $40 \%$ vs. $25 \%$ ) and fewer with poor vision (visual acuity $\leq 35 \log$ MAR letters [20/200], $10 \%$ vs. $25 \%$ ) compared with noncompleters. There was no difference in lesion size $(P=0.806)$ or type $(P=0.745)$ between completers and noncompleters.

\section{Twenty-Four Months Visual Acuity Outcomes}

Mean (SD) visual acuity for completers increased from 61.4 (17.4) letters (20/60) at baseline to 67.4 (17.7) letters $(20 / 45$; +6.0 letters [95\% CI: 3.3-8.5]; $P<$ 0.001). From baseline to 24 months, the proportion of eyes with visual acuity $\geq 70$ letters (20/40) increased (40\%-58\%, $P<0.001$ ), whereas the proportion with visual acuity $\leq 35$ letters $(20 / 200)$ remained at $10 \%(P=$ $0.547)$. Ninety-eight per cent of eyes starting with visual acuity $\geq 70$ letters (20/40) maintained it 24 months after initiating treatment. Loss of 3 lines ( $\geq 15$ letters) was avoided by $93 \%$ of eyes. As shown in Figure 1, the mean visual acuity peaked after about 12 months after beginning therapy before declining slowly.

\section{Twenty-Four Months Visit and Injection Frequency Outcomes}

There was a mean of 7.8 (2.1) injections received in the first year, reducing to 5.7 (2.6) injections in the second year for completers. Overall, completers received a mean of 13.6 (4.2) injections over 24 months of aflibercept treatment. The mean number of visits was 8.7 in the first year, 6.5 in the second, and 15.1 over the 24-month follow-up period for completers, which was slightly greater than the mean number of injections received. For completers, an injection was received in $92 \%$ of visits overall. An injection was received in $96 \%$ of visits when an eye was graded as active, and in $84 \%$ of visits when it was graded as inactive, consistent with a treat and extend approach. The visits without injection

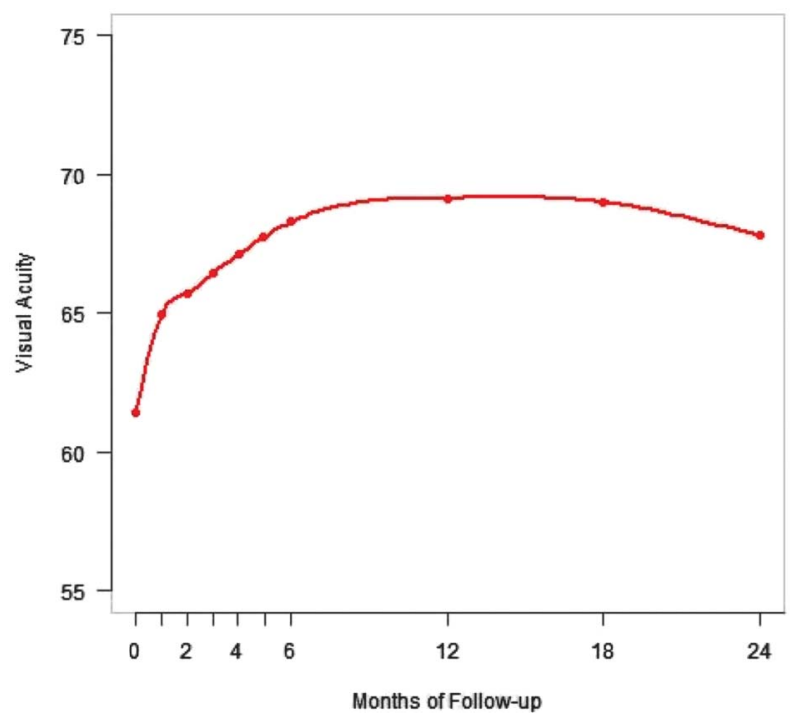

Fig. 1. Locally weighted scatterplot smoothing curve showing the mean visual acuity for eyes completing 24 months of follow-up. 
were unrelated to the $T \& E$ schedule because some patients in this study had postinjection irritation or came for a check-up, hence the difference to a perfect T\&E wherein $100 \%$ of visits injections would have been given.

Most (76\%) eyes were treated at 4 weekly intervals for the first 3 months. From 4 to 6 months after the first visit, $34 \%$ of eyes had been extended to a 6-weekly and $34 \%$ to an 8 -weekly interval. At 12 months, $25 \%$ had been extended to an interval of 9 weeks or greater. By 24 months, $24 \%$ of eyes were being treated at an interval of 12 weeks or greater (4\%; Figure 2).

The median injection interval for the first 3 injections was 28 days, increasing to 49 days for the fourth injection. Most eyes were extended by either 2 to 4 weeks $(31 \%)$ or less than 2 weeks $(43 \%)$ for the fourth injection. The remaining eyes were extended for longer than 4 weeks, with 7\% being extended by 2 months after the first 3 injections. An overview of treatment intervals is given in Table 2 .

For the subset of completers, $72(53 \%)$ eyes were treated at 4 weeks intervals for the first 3 injections. The median (IQR) injection interval was 28 (28-32) days between the first and second injections, and 29 (28-42) days between the second and third injections.

\section{First Recorded Grading of Inactivity}

The median time and number of injections to first recorded inactive CNV grading was 71 days (IQR 31221) and 3 injections (IQR 2-4), respectively. Most eyes $(82 \%)$ became inactive within the first year, with only $10 \%$ remaining active at the end of 24 months

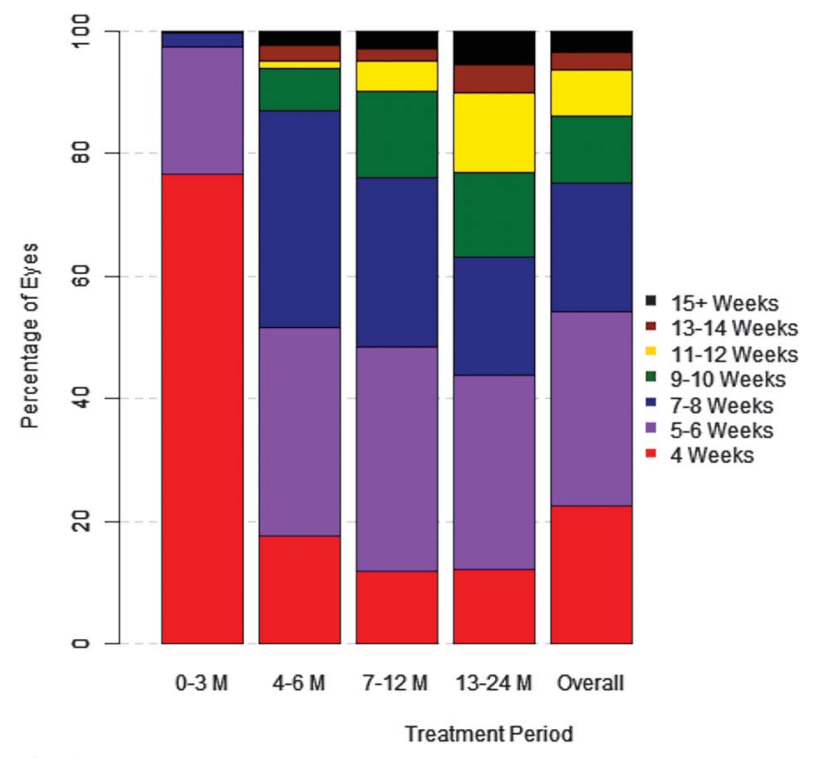

Fig. 2. Percentage of eyes and their mean treatment interval during various periods since beginning aflibercept monotherapy for completers. follow-up (Figure 3). For the eyes that became inactive, $68 \%$ required 3 or fewer injections to become inactive.

\section{Outcomes in Noncompleters}

The proportion of eyes not completing 24 months of follow-up during the study period was 60 out of the 212 eligible eyes (28\%). Mean visual acuity change when eyes were lost to follow-up was +3.9 letters (95\% CI: -1.1 to 8.9 ) and did not differ between completers and noncompleters $(P=0.477)$. Median (IQR) time to loss of follow-up was 394 days (239577 days; Figure 4). Noncompleters received a mean (SD) of 7.8 (4.0) injections over 9.3 (4.6) visits until loss to follow-up.

\section{Outcomes in Switchers}

The proportion of eyes switching treatments before completing 24 months of follow-up was 16 out of the 212 eligible eyes (8\%). Mean visual acuity change at time of switching was 7.9 letters (95\% CI: 3.0-12.8) and did not differ between completers and switchers $(P=0.451)$. Interestingly, eyes that switched treatment had higher baseline visual acuity, a higher proportion with good vision ( $\geq 70 \operatorname{logMAR}$ letters; 20/40), and a lower proportion with poor vision $(\leq 35 \log$ MAR letters; 20/200). Median (IQR) time to switching was 169 days (91-376 days; Figure 5). Switchers received a mean (SD) of 6.6 (3.3) injections over 6.7 (4.1) visits of aflibercept until switching to ranibizumab.

\section{Outcomes in All Eyes}

Visual outcomes for all eyes, that is completers, noncompleters, and switchers, are shown in Table 3. When noncompleters and switchers were included using last observation carried forward, the mean change in visual acuity from baseline was +5.6 letters (95\% CI: 3.3-7.7).

\section{Ocular Safety}

Over the course of the study period, 10 adverse events resulting from 2,415 injections were observed in all eyes, including noncompleters and switchers: 2 eyes had hemorrhage reducing best-corrected visual acuity by $>15$ letters, and 3 eyes had retinal pigment epithelium tears.

\section{Discussion}

We report herein 24-month outcomes of a real-life cohort of patients with nAMD receiving aflibercept as 
Table 2. Treatment Intervals During the 24-Month Study Period

\begin{tabular}{|c|c|c|c|c|c|c|c|}
\hline & $\begin{array}{c}4 \text { Weeks, } \\
\%\end{array}$ & $\begin{array}{c}\text { 5-6 Weeks, } \\
\%\end{array}$ & $\begin{array}{c}\text { 7-8 Weeks, } \\
\%\end{array}$ & $\begin{array}{c}9-10 \text { Weeks, } \\
\%\end{array}$ & $\begin{array}{c}11-12 \text { Weeks, } \\
\%\end{array}$ & $\begin{array}{c}13-14 \text { Weeks, } \\
\%\end{array}$ & $\begin{array}{c}15+\text { Weeks } \\
\%\end{array}$ \\
\hline 0-3 Months & 76 & 21 & 2 & 0 & 0 & 0 & 0 \\
\hline 4-6 Months & 18 & 34 & 34 & 9 & 1 & 2 & 2 \\
\hline 7-12 Months & 12 & 37 & 26 & 15 & 5 & 2 & 3 \\
\hline 13-24 Months & 12 & 32 & 19 & 14 & 13 & 5 & 6 \\
\hline $\begin{array}{l}\text { Overall } \\
\quad \text { Percentage }\end{array}$ & 23 & 32 & 20 & 12 & 7 & 3 & 4 \\
\hline
\end{tabular}

Four weeks, 10-34 days; 5-6 weeks, 35-48 days; 7-8 weeks, 49-61 days; 9-10 weeks, 62-76 days; 11-12 weeks, 77-90 days; 13-14 weeks, 91-104 days; $15+$ weeks, $>105$ days.

a sole treatment under a treat and extend regimen. Two years after starting therapy, we found a mean gain of +6.0 $\log$ MAR letters in a selected cohort treated in routine clinical practice. The number of eyes with good vision $(\geq 20 / 40)$ increased from $40 \%$ to $58 \%$ and $98 \%$ of eyes starting with a visual acuity of $\geq 70$ letters (20/40) maintained this level. In $93 \%$ of eyes a loss of $\geq 15 \log$ MAR letters was avoided.

Ever since anti-vascular endothelial growth factor drugs became available to treat nAMD, clinicians have been trying to find ways to deliver the optimal treatment for an individual patient whilst minimizing the burden of treatment and potential side effects. Due to its earlier availability, information is now available on the outcomes of PRN and T\&E regimens using ranibizumab for $\mathrm{nAMD}$ in routine clinical practice. ${ }^{16}$ Although no direct comparison between PRN and T\&E has been published, it seems that T\&E with ranibizumab may result in better outcomes than PRN. ${ }^{16}$

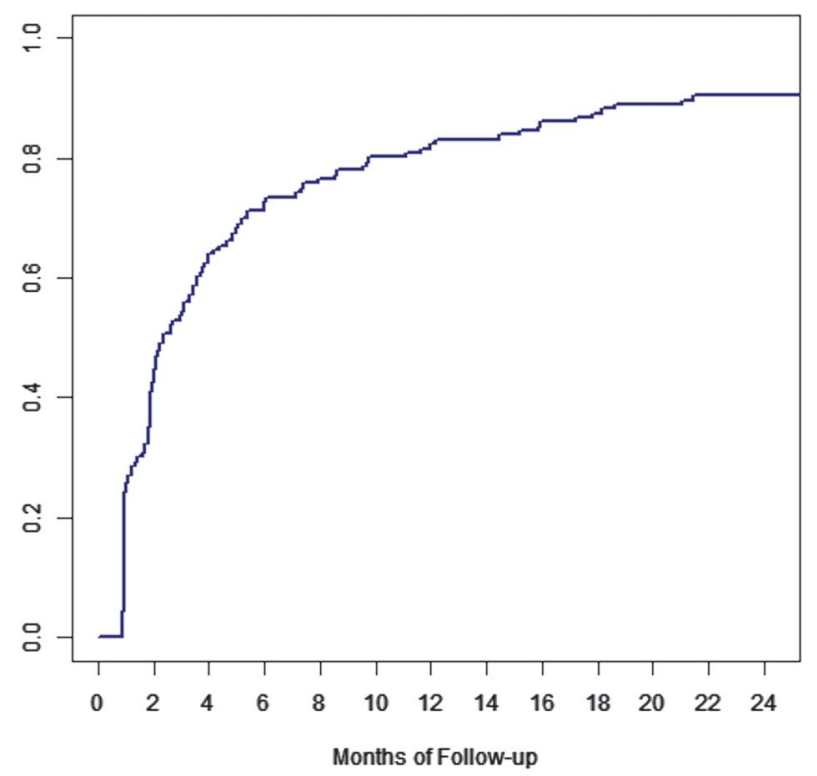

Fig. 3. Kaplan-Meier survival analysis of length of time to first inactivation of choroidal neovascularization for completers.
Aflibercept for nAMD was initially studied in the vascular endothelial growth factor Trap-Eye: Investigation of Efficacy and Safety in Wet AMD studies (VIEW) randomized clinical trial. ${ }^{21}$ In VIEW, a fixed treatment was mandated during the first year only and after this a "capped PRN" approach was used. ${ }^{21}$ The VIEW study reported a maximum gain of visual acuity at 52 weeks (fixed treatment phase) followed by a slow decline in visual acuity thereafter. The VIEW study found a mean gain in visual acuity of +8 letters in a cohort that included noncompleters using last observation carried forward.

Randomized clinical trials usually have strict entry criteria and a defined protocol on how and when treatment is to be given. Patients from real world practice may not always fit these entry criteria but still receive treatment. Lower or higher mean visual acuity at start of therapy can lead to bias as eyes with lower visual acuity have a higher potential to gain visual acuity, whereas eyes with a relatively high visual

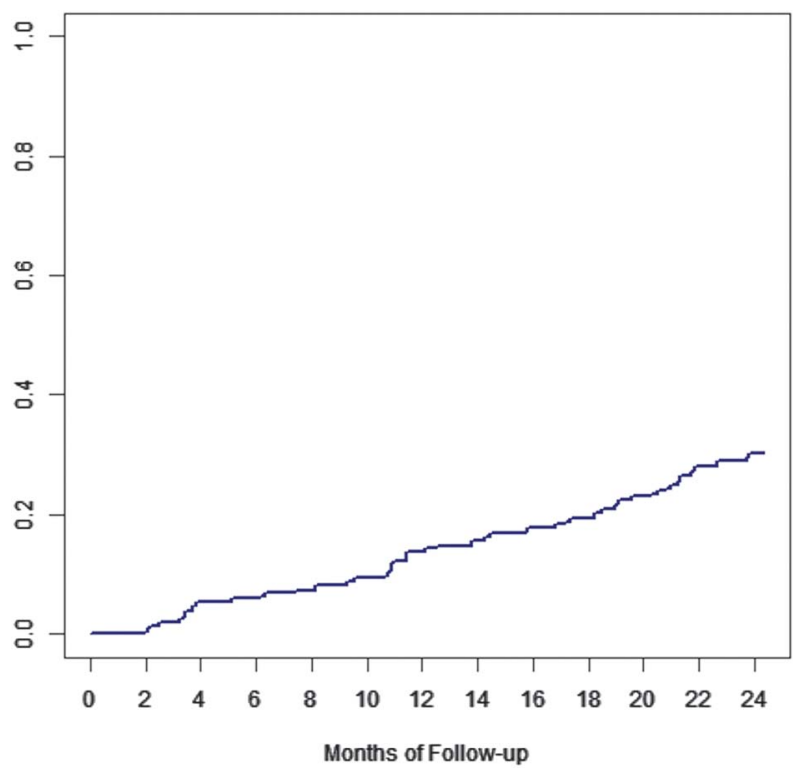

Fig. 4. Kaplan-Meier survival analysis of length of time to dropout. 


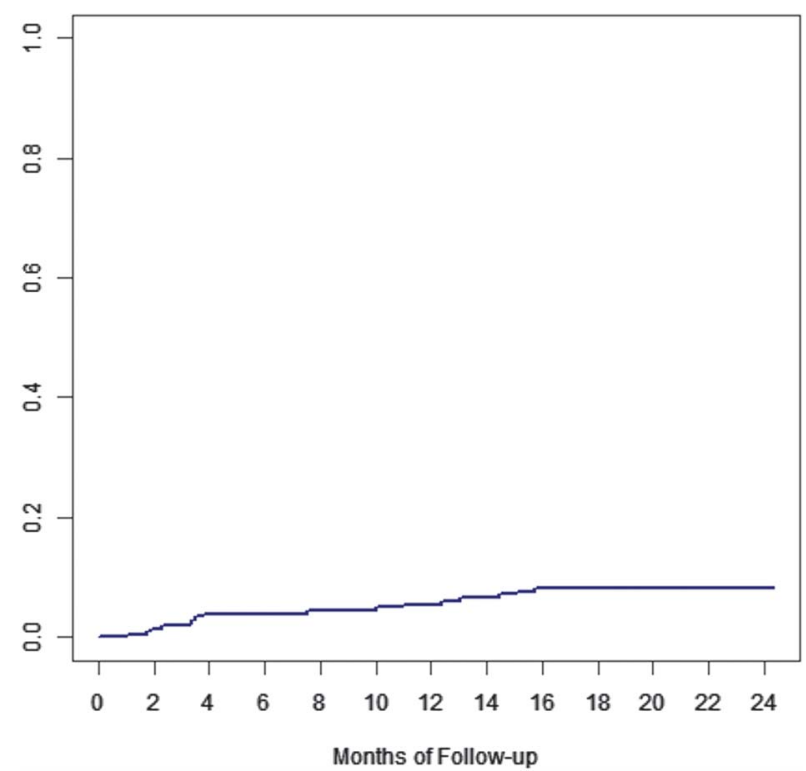

Fig. 5. Kaplan-Meier survival analysis of length of time to switching.

acuity have little chance of gaining more but have greater potential to lose vision. ${ }^{10,22}$

Loss to follow-up may bias in favor of a treated group if the patients who drop out have poorer vision. Approximately, $36 \%$ of eyes did not complete 24 months of aflibercept monotherapy in the cohort we studied. Of these, $28 \%$ (60 of 212 eyes) did not complete the 24-month follow-up and 8\% (16 of 212 eyes) switched to ranibizumab. Although noncompleters had a lower proportion of eyes with visual acuity $\geq 70 \log$ MAR letters (20/40) at baseline, a higher proportion of eyes with visual acuity $\leq 35 \log$ MAR letters (20/200), and a lower mean visual acuity (Table 1), an analysis of all eyes using a last observation carried forward method did not show a significant reduction in mean outcomes (5.6 gain in all eyes vs. 6.0 letter gain in completers; Table 3). Noncompleters had similar proportions of eyes with a $\geq 10$ letter loss or gain and $a \geq 15$ letter loss at the time of dropping out compared with completers after 24 months. At the time of their last recorded visit, mean visual acuity gain of noncompleters was +4 letters. This suggests that most eyes that dropped out did not do so due to poor visual outcomes but other reasons. Similarly, the 16 eyes that switched treatment seemed to have had a good visual acuity response to treatment at the time of the switch, with a high proportion of eyes with good visual acuity at baseline and a gain of $7.4 \log$ MAR letters when treatments were switched. As reasons for noncompletion and for switching treatments were not recorded, it is purely speculative why noncompletion and switching occurred.

A direct comparison of $\mathrm{T} \& \mathrm{E}$ outcomes from real world practice between aflibercept and ranibizumab is difficult. Two prospective trials using a T\&E approach and ranibizumab reported 24-month outcomes of a mean gain in visual acuity from +8 and $+10 \log$ MAR letters. ${ }^{14,15}$ This is comparable to the results of current study. The mean baseline visual acuity of these studies was $51 \log$ MAR letters $(20 / 100)^{15}$ and $60 \log$ MAR letters $(20 / 60)$, respectively,,${ }^{14}$ that is similar to the current analysis (Table 1). Although baseline visual acuity is a strong predictor for final visual acuity, ${ }^{10,11}$ outcomes with respect to mean gain in visual acuity are comparable.

We have previously published real world outcomes from a large cohort of nearly 1,200 eyes where ranibizumab (and to a lesser extent bevacizumab and aflibercept) was used in a T\&E approach for treatment of nAMD. ${ }^{11}$ Mean visual acuity gains were $+5.3 \log$ MAR letters at 24 months for eyes completing 24

Table 3. Visual Outcomes for All Eyes, 24-Month Monotherapy Completers, Noncompleters, and Switchers

\begin{tabular}{lcccc}
\hline & Completers & Noncompleters & Switchers & All Eyes \\
\hline No. eyes & 136 & 60 & 16 & 212 \\
Baseline VA, mean (Snellen; SD) & $61.4(20 / 63 ; 17.4)$ & $50.1(20 / 100 ; 22.5)$ & $63.2(20 / 55 ; 18.9)$ & $58.3(20 / 65 ; 19.7)$ \\
Final VA, mean (SD) & $67.4(20 / 47 ; 17.7)$ & $54.0(20 / 83 ; 24.6)$ & $70.6(20 / 50 ; 13.2)$ & $63.9(20 / 53 ; 20.6)$ \\
$\Delta$ VA (95\% CI) & $6.0(3.3$ to 8.5) & $3.9(-1.1$ to 8.9) & $7.4(2.7$ to 12.0) & $5.6(3.3$ to 7.7$)$ \\
Gain $\geq 10$ letters, n (\%) & $48(35)$ & $23(38)$ & $5(31)$ & $76(36)$ \\
Loss $\geq 10$ letters, n (\%) & $15(11)$ & $9(15)$ & $0(0)$ & $24(11)$ \\
Avoid $\geq 15$ letters loss, n (\%) & $126(93)$ & $54(90)$ & $16(100)$ & $196(93)$ \\
VA $\geq 70$ (20/40; baseline/final), \% & $40 / 58$ & $25 / 42$ & $44 / 69$ & $36 / 54$ \\
VA $\leq 35$ (20/200; baseline/final), \% & $10 / 10$ & $25 / 23$ & $6 / 6$ & $14 / 13$ \\
Injections, mean (SD) & $13.6(4.2)$ & $7.8(4.0)$ & $6.6(3.3)$ & $11.4(5.1)$ \\
Visits, mean (SD) & $15.1(3.7)$ & $9.3(4.6)$ & $6.7(4.1)$ & $12.8(5.0)$ \\
\hline
\end{tabular}

Completers include all eyes completing 24 months of aflibercept monotherapy.

Noncompleters include eyes that have not yet completed 24 months of follow-up and the last VA recorded.

Switchers include eyes that received $\geq 2$ injections of ranibizumab before completing 24 months of aflibercept monotherapy.

All eyes include completers, noncompleters, and switchers.

VA, visual acuity. 
months of treatment. Mean visual acuity at baseline in that analysis on ranibizumab was $57 \log$ MAR letters (20/70). The current visual acuity results using aflibercept are slightly better, with a mean gain in visual acuity in completers of +6.0 logMAR letters, however, this cohort was treated at a later time than the study of ranibizumab eyes, which was conducted on eyes starting treatment from 2007 to $2012 .{ }^{11}$ A steady improvement in 24 months outcomes over time for the ranibizumab eyes was observed $(+2.7$ letters for 9.7 injections over 24 months to +7.8 letters for 14.2 injections, respectively) in that study, suggesting a potential learning effect of clinicians. The current data add to the growing literature on the T\&E regimen, which has hitherto been predominantly on treatment with ranibizumab. We found that good outcomes can also be achieved using aflibercept in real world practice.

Although there does not seem to be a great difference in 24-month visual acuity outcomes between aflibercept and ranibizumab, there may have been a difference in treatment intervals. During the second year of treatment, only $12 \%$ of eyes treated with aflibercept were still on 4-weekly treatments, compared with $19 \%$ for ranibizumab. ${ }^{11}$ Eyes on aflibercept were also treated at somewhat longer intervals during the second year, with $37 \%$ of eyes treated $>8$ weeks compared with $34 \%$ of eyes using ranibizumab. Again, the fact the studies were conducted on patients being treated during different periods of time over which treatment approaches have very likely changed suggests that comparisons may not be valid.

This analysis has several strengths and limitations. Observational studies provide data that reflect the ability of a drug to achieve its intended purpose in the real world. Although the quality of data in observational studies may be variable, the FRB! system includes quality assurance measures that identify out of range and missing data. ${ }^{17}$

Factors such as preferences for a certain drug in a particular situation cannot be accounted for, and reasons for switching treatments. All of the clinicians participating to the current analysis were established retina specialists and are experienced in nAMD treatment. Patients were not, however, randomly assigned to receive aflibercept as they would have been in a randomized clinical trial. Aflibercept may have been preferred over ranibizumab, which was also freely available, in some eyes. It has been suggested, for example, that large retinal pigmented epithelium detachments, which were not specifically evaluated at baseline, may respond well to aflibercept. ${ }^{23}$ Our recent analysis has revealed that choice of treatment patterns of ranibizumab and aflibercept amongst the practitioners participating in this study have been very similar since aflibercept became available, indicating that there is no perceived superiority of one drug over the other. ${ }^{24}$

Our study provides evidence that is complementary to the findings of randomized clinical trials. Overall we found that a $T \& E$ approach using aflibercept for nAMD can produce good outcomes in routine clinical practice.

Key words: age-related macular degeneration, aflibercept, treat and extend, neovascular, $\mathrm{CNV}$, choroidal neovascularization.

\section{Acknowledgments}

Fight Retinal Blindness Investigators: Eye Associates, Sydney, NSW (M.C.G., Dr. Adrian Hunt); Canberra Hospital, Garran, ACT (R.W.E.; Dr. C. Dayajeewa); Retina Associates, Chatswood, NSW (A/Prof. S. FraserBell, Dr. C. Younan); Centre for Eye Research Australia, East Melbourne, VIC (R.G.); Marsden Eye Specialists, Parramatta, NSW (J.J.A.); Victoria Parade Eye Consultants, Fitzroy, VIC (R.G., Dr. A. Harper, Dr. J. O'Day, and Dr. M. Daniell); Cairns Eye and Laser Clinic, Manoora, QLD (Dr. A. Field); Doncaster Eye Centre, VIC (Dr. L. P. Chow); Berwick Eye Centre, Northern Rivers Eye Surgeons, Lismore, NSW (Dr. S. Wickremasinghe); Specialists Eye Group, Glen Waverly, VIC (Dr. S. Wickremansinghe, Dr. L. P. Chow; and Dr. A. Cohn); University Hospital Zurich, University of Zurich, Zurich Switzerland (D.B.); Gladesville Eye Specialists, Gladesville, NSW (Dr. S. Young); Hornsby Eye Specialists, Hornsby, NSW (Dr. S. Lal); Gosford Eye Surgeons, Gosford, NSW (Dr. S. Young); Retina Specialist Auckland, NZ (Dr. R. Barnes); Les Manning Practice, Brisbane, QLD (Dr. L. Manning); Eyemedics, Adelaide, SA (Dr. N. Saha); Nepean Valley Eye Surgeons, Penrith, NSW (Dr. Gayatri Banerjee); Southeastern Eye Care, Miranda, NSW (Dr. B. Swamy); Dr Phillip Windle's Practice, Rockville QLD (Dr. P. Windle); Care Foresight, Hamilton, NSW (Dr. A. Dunlop); Cranbourne Eye Surgery, Cranbourne, VIC (Dr. K. Michalova); Park Street Eye Clinic Tauranga, Tauranga, NZ (Dr. A. Thompson); Midwest Ophthalmology, Orange, NSW (Dr. K. C. Tang); Victorian Eye Surgeons, Footscray, VIC (Dr. A. Cohn); Armadale Eye Clinic, Armadale, VIC (Dr. A. Cohn); Bundaberg Eye Clinic, Bundaberg, QLD (Dr. I. McLean); Dr. Alex Amini's Practice, Mount Waverley, VIC (Dr. A. Amini).

\section{References}

1. Heier JS, Brown DM, Chong V, et al. Intravitreal aflibercept (VEGF trap-eye) in wet age-related macular degeneration. Ophthalmology 2012;119:2537-2548. 
2. CATT Research Group, Martin DF, Maguire MG, et al. Ranibizumab and bevacizumab for neovascular age-related macular degeneration. N Engl J Med 2011;364:1897-1908.

3. Rosenfeld PJ, Brown DM, Heier JS, et al. Ranibizumab for neovascular age-related macular degeneration. N Engl J Med 2006;355:1419-1431.

4. Brown DM, Kaiser PK, Michels M, et al. Ranibizumab versus verteporfin for neovascular age-related macular degeneration. N Engl J Med 2006;355:1432-1444.

5. Chakravarthy U, Harding SP, Rogers CA, et al. Alternative treatments to inhibit VEGF in age-related choroidal neovascularisation: 2-year findings of the IVAN randomised controlled trial. Lancet 2013;382:1258-1267.

6. IVAN Study Investigators, Chakravarthy U, Harding SP, et al. Ranibizumab versus bevacizumab to treat neovascular agerelated macular degeneration: one-year findings from the IVAN randomized trial. Ophthalmology 2012;119:1399-1411.

7. Martin DF, Maguire MG, Fine SL, et al. Ranibizumab and bevacizumab for treatment of neovascular age-related macular degeneration: two-year results. Ophthalmology 2012;119:1388-1398.

8. Busbee BG, Ho AC, Brown DM, et al. Twelve-month efficacy and safety of $0.5 \mathrm{mg}$ or $2.0 \mathrm{mg}$ ranibizumab in patients with subfoveal neovascular age-related macular degeneration. Ophthalmology 2013;120:1046-1056.

9. Ho AC, Busbee BG, Regillo CD, et al. Twenty-four-month efficacy and safety of $0.5 \mathrm{mg}$ or $2.0 \mathrm{mg}$ ranibizumab in patients with subfoveal neovascular age-related macular degeneration. Ophthalmology 2014;121:2181-2192.

10. Writing Committee for the UKA-RMDEMRUG. The neovascular age-related macular degeneration database: multicenter study of 92,976 ranibizumab injections: report 1: visual acuity. Ophthalmology 2014;121:1092-1101.

11. Arnold JJ, Campain A, Barthelmes D, et al. Two-year outcomes of "treat and extend" intravitreal therapy for neovascular age-related macular degeneration. Ophthalmology 2015;122: 1212-1219.

12. Rayess N, Houston SK III, Gupta OP, et al. Treatment outcomes after 3 years in neovascular age-related macular degeneration using a treat-and-extend regimen. Am J Ophthalmol 2015;159:3-8.e1.
13. Toalster N, Russell M, Ng P. A 12-month prospective trial of inject and extend regimen for ranibizumab treatment of agerelated macular degeneration. Retina 2013;33:1351-1358.

14. Wykoff CC, Croft DE, Brown DM, et al. Prospective trial of treat-and-extend versus monthly dosing for neovascular agerelated macular degeneration: TREX-AMD 1-year results. Ophthalmology 2015;122:2514-2522.

15. Abedi F, Wickremasinghe S, Islam AF, et al. Anti-VEGF treatment in neovascular age-related macular degeneration: a treat-and-extend protocol over 2 years. Retina 2014;34: 1531-1538.

16. Chin-Yee D, Eck T, Fowler S, et al. A systematic review of as needed versus treat and extend ranibizumab or bevacizumab treatment regimens for neovascular age-related macular degeneration. Br J Ophthalmol 2015. Epub ahead of print.

17. Gillies MC, Walton R, Liong J, et al. Efficient capture of highquality data on outcomes of treatment for macular diseases: the fight retinal blindness! Project. Retina 2014;34:188-195.

18. Unnebrink K, Windeler J. Intention-to-treat: methods for dealing with missing values in clinical trials of progressively deteriorating diseases. Stat Med 2001;20:3931-3946.

19. Cleveland WS, Devlin SJ, Grosse E. Regression by local fitting. J Econom 1988;37:87-114.

20. R: A Language and Environment for Statistical Computing Vienna, Austria: Foundation for Statistical Computing; 2016.

21. Schmidt-Erfurth U, Kaiser PK, Korobelnik JF, et al. Intravitreal aflibercept injection for neovascular age-related macular degeneration: ninety-six-week results of the VIEW studies. Ophthalmology 2014;121:193-201.

22. Gillies MC, Campain A, Barthelmes D, et al. Long-term outcomes of treatment of neovascular age-related macular degeneration: data from an observational study. Ophthalmology 2015;122:1837-1845.

23. Shah CP. Anti-VEGF effect in eyes with retinal pigment epithelium elevation in the VIEW 1 and VIEW 2 studies of wet AMD patients. AAO Meet 2013;2013.

24. Gillies MC, Nguyen V, Daien V, et al. Twelve-month outcomes of ranibizumab vs. aflibercept for neovascular agerelated macular degeneration: data from an observational study. Ophthalmology 2016;123:2545-2553. 